\title{
Weekend new patient reviews in psychiatry: evaluation of activity over 3 months
}

\author{
Michael Rutherford, ${ }^{1}$ Mark Potter ${ }^{1}$
}

BJPsych Bulletin (2017) 41, 337-340, doi: 10.1192/pb.bp.117.056291

${ }^{1}$ South West London and St George's Mental Health NHS Trust

Correspondence to Michael Rutherford (michael.rutherford@swlstg-tr.nhs.uk)

First received 6 Feb 2017, final revision 22 Mar 2017, accepted 24 May 2017

(C) 2017 The Authors. This is an openaccess article published by the Royal College of Psychiatrists and distributed under the terms of the Creative Commons Attribution License (http:// creativecommons.org/licenses/by/ 4.0), which permits unrestricted use distribution, and reproduction in any medium, provided the original work is properly cited.
Aims and method South West London and St George's Mental Health NHS Trust developed a system of weekend new patient reviews by higher trainees to provide senior medical input 7 days a week. To evaluate the effectiveness of these reviews, the notes for all patients admitted over 3 months were examined. The mean length of stay for patients before and after the introduction of the weekend new patient reviews were compared via unpaired $t$-test.

Results A total of 88 patients were seen: $84.4 \%$ of patients were seen within $24 \mathrm{~h}$ of admission. Higher trainees instituted some changes in $78.9 \%$ of patients. The most frequent action was to modify medication, in $47.8 \%$. The average length of stay after the introduction of weekend reviews was not significantly different.

Clinical implications Weekend reviews of newly admitted patients by higher trainees is a feasible method for providing senior input to patients admitted out of hours.

Declaration of interest None.
Medical specialties of various types are increasingly being requested to deliver senior-led care throughout weekends and bank holidays. This 7-day working is felt to be potentially beneficial for patient care and has been started by many acute specialties. The Academy of Medical Royal Colleges released a report in 2013 outlining how this could be achieved for different specialties, including psychiatry. ${ }^{1}$ They recommended that $21-30 \%$ of psychiatric in-patients would benefit from a daily consultant-led review; mainly those who have been newly admitted or are clinically unstable. They stated that all new admissions, especially those under the Mental Health Act 1983, should receive a review the following day to initiate a treatment plan, including medication, observation levels, physical and psychosocial investigations and referrals.

The Academy of Medical Royal Colleges also advised that their recommendations were considered in light of the requirements of the local organisation as practice is likely to vary depending on geographic location, organisation size, on-call staffing and number of in-patient units. They also acknowledged that to achieve these outcomes, certain interventions and investigations would need to be available, such as pathology access.

\section{Method}

South West London and St George's Mental Health NHS Trust developed a system of weekend ward reviews led by higher trainees with consultant advice. The higher trainees in the Trust were on a full-shift on-call rota with 09:00 $\mathrm{h}$ to
21:00 h shifts on weekends and bank holidays. Patients admitted out of hours on Fridays, Saturdays or up to 09:00 h on Sunday morning are reviewed by the on-call higher trainee the next day. Patients admitted after 09:00 h on Sunday are reviewed on Monday by the ward team, unless it is a bank holiday, in which case they are reviewed by the higher trainee on call that day. After the higher trainee has completed their reviews for a given site, they contact the on-call consultant to discuss the cases and ensure the management plans instituted are appropriate. This occasionally led to changes in treatment plan. This provides an opportunity for supervision and training and ensures consultant input. The role of the reviews was to ensure that the patients received prompt assessment by a senior clinician and a comprehensive management plan could be instituted. They were not intended to facilitate immediate discharge, although it was hoped that earlier treatment would reduce the time patients had to spend on the ward.

To evaluate the activity involved in the weekend new patient reviews, the notes for all patients admitted between 17:00 h on Friday and 09:00 h on Sunday between 1 January 2016 and 31 March 2016 were identified via the RiO system used by the Trust. This provided information regarding the timing of their admission. The clinical notes of each of these patients were examined to determine the reason for their admission, when they were seen by the on-call higher trainee, the diagnosis made and any actions taken as a result of the weekend review. The mean length of stay for patients admitted between 17:00 h on Friday and 09:00 h on Sunday and 1 January 2015 to 31 March 2015 were also compared 
via unpaired $t$-test. The number of serious untoward incidents in each time period was also compared via Mann-Whitney $U$-test.

\section{Results}

A total of 88 patients were seen over the 3 -month period. This equates to 6.8 patients appropriate for senior review each weekend.

Of those admitted, $46(52.3 \%)$ were male. The average age was 41.9 years (range $18-84$, s.d. $=17.8$ ). For males the average age was 41.4 years (range $18-84$, s.d. $=19.6$ ) and for females it was 42.5 years (range $19-83$, s.d. $=15.9$ ). These differences were not significant on $t$-test.

The time from admission to senior review is indicated in Table 1. A total of 11 patients were not seen at all. Of these, 4 were admitted via the 136 Suite in the Trust.

Diagnoses were made by the higher trainee in 73 patients. The other 15 patients were diagnosed during later assessments. These diagnoses are shown in Table 2. There were no significant differences between patients diagnosed by the higher trainee or at a later point on two-tailed $z$-tests.

The interventions made or recommended by higher trainees for the 77 patients reviewed during weekends are shown in Table 3. This does not include them indicating their agreement with actions made by clinicians who saw the patients before them. Again, the number of interventions shown exceeds the number of patients.

\begin{tabular}{|c|c|c|c|}
\hline $\begin{array}{l}\text { Review } \\
\text { within }\end{array}$ & $\begin{array}{l}\text { Number } \\
\text { of } \\
\text { patients }\end{array}$ & $\begin{array}{c}\text { Cumulative } \\
\text { number }\end{array}$ & $\begin{array}{l}\text { Cumulative } \\
\text { percentage of } \\
\text { patients seen }\end{array}$ \\
\hline 12 hours & 17 & 17 & 22.1 \\
\hline 24 hours & 48 & 65 & 84.4 \\
\hline 36 hours & 8 & 73 & 94.8 \\
\hline 48 hours & 4 & 77 & 100 \\
\hline
\end{tabular}

The length of stay for patients admitted between Friday 17:00 $\mathrm{h}$ and Sunday 09:00 h between 1 January and 31 March in 2015 was 26 days (s.d. = 37) and for the same period of time in 2016 the length of stay was 28 days (s.d. $=43$ ). This was not significant.

The number of serious untoward incidents between January and March 2015 was 13, and during the same period in 2016 it was 28 ; this was significant $(P=0.0652)$. However, when serious untoward incidents were limited to those occurring in acute services and out of hours, there was 1 incident between January and March 2015 and 3 incidents in the same time period in 2016; these numbers were too low to be analysed and so did not reach significance.

\section{Discussion}

A substantial number of patients, 88 in total, were eligible for weekend review over the 3 months covered by the service evaluation and 77 of these were actually seen. A substantial minority of those not seen were admitted through the Trust's dedicated 136 Suite. This mode of admission may be a weak point in the current system, possibly as a patient detained to the suite could be viewed as having been admitted at that point, despite still awaiting formal assessment and possible admission. Patients admitted via the 136 Suite should still have been reviewed the following day.

Of those patients seen by the higher trainees, the vast majority $(84.4 \%)$ were seen within $24 \mathrm{~h}$ and most of the rest, up to $94.8 \%$, were seen within $36 \mathrm{~h}$. Many of those seen between 24 and $36 \mathrm{~h}$ had been admitted during the morning on a Saturday and the higher trainee was unable to see them until the afternoon on Sunday. A small number (5.2\%) were seen after $36 \mathrm{~h}$ had elapsed. The reasons for this are unclear but could be as a result of temporary limited provision of higher trainee cover due to illness.

The characteristics of the patients admitted do not appear to be remarkable, although it would have been useful to have a comparison group of patients admitted during the week to determine whether there were significant differences between the two, in terms of demographics,

\begin{tabular}{|c|c|c|c|c|c|c|}
\hline \multirow[b]{2}{*}{ Diagnoses } & \multicolumn{2}{|c|}{ Diagnosed by higher trainee } & \multicolumn{2}{|c|}{ Diagnosed subsequently } & \multicolumn{2}{|c|}{ Total diagnoses } \\
\hline & $\begin{array}{c}\text { Number } \\
\text { of patients }\end{array}$ & $\begin{array}{l}\text { Percentage } \\
\text { of patients }\end{array}$ & $\begin{array}{l}\text { Number } \\
\text { of patients }\end{array}$ & $\begin{array}{l}\text { Percentage } \\
\text { of patients }\end{array}$ & $\begin{array}{l}\text { Number } \\
\text { of patients }\end{array}$ & $\begin{array}{l}\text { Percentage } \\
\text { of patients }\end{array}$ \\
\hline Psychosis & 31 & 42.5 & 8 & 53.3 & 39 & 44.3 \\
\hline Depression & 17 & 23.3 & 7 & 46.7 & 24 & 27.2 \\
\hline Mania/hypomania & 7 & 9.6 & 1 & 6.7 & 8 & 9.1 \\
\hline Alcohol or substance misuse & 7 & 15.6 & 1 & 6.7 & 8 & 9.1 \\
\hline Personality disorder & 12 & 2.6 & 3 & 20 & 15 & 17 \\
\hline Anxiety and stress-related disorders & 2 & 1.3 & 2 & 13.3 & 4 & 4.5 \\
\hline Eating disorder & 1 & 5.2 & 1 & 6.7 & 2 & 2.3 \\
\hline Developmental disorders & 4 & 1 & 2 & 13.3 & 6 & 6.8 \\
\hline Physical illness & 1 & 1.3 & 0 & 0 & 1 & 1.1 \\
\hline Unclear & 1 & 1.3 & 1 & 6.7 & 2 & 2.3 \\
\hline
\end{tabular}




\begin{tabular}{|c|c|c|}
\hline Intervention & Total, $n$ & $\%$ \\
\hline $\begin{array}{l}\text { Start medication } \\
\text { Regular antipsychotic } \\
\text { As required antipsychotic } \\
\text { Mood stabiliser } \\
\text { Antidepressant } \\
\text { Sedation } \\
\text { Hypnotic } \\
\text { Physical medication } \\
\text { Nicotine replacement } \\
\text { Total in which medication started }\end{array}$ & $\begin{array}{r}8 \\
2 \\
1 \\
8 \\
5 \\
3 \\
3 \\
1 \\
24\end{array}$ & $\begin{array}{r}10.4 \\
2.6 \\
1.3 \\
10.4 \\
6.5 \\
3.9 \\
3.9 \\
1.3 \\
31.2\end{array}$ \\
\hline $\begin{array}{l}\text { Increase medication } \\
\text { Regular antipsychotic } \\
\text { Antidepressant } \\
\text { Sedation } \\
\text { Other psychotropics }\end{array}$ & $\begin{array}{l}1 \\
2 \\
3 \\
1\end{array}$ & $\begin{array}{l}1.3 \\
2.6 \\
3.9 \\
1.3\end{array}$ \\
\hline $\begin{array}{l}\text { Stop medication } \\
\text { Antipsychotic } \\
\text { Sedation } \\
\text { Opiate replacement } \\
\text { All } \\
\text { Total medication changes }\end{array}$ & $\begin{array}{r}1 \\
1 \\
1 \\
2 \\
37\end{array}$ & $\begin{array}{r}1.3 \\
1.3 \\
1.3 \\
2.6 \\
47.8 \\
\end{array}$ \\
\hline $\begin{array}{l}\text { Recommended interventions } \\
\text { Regular antipsychotic } \\
\text { Psychotherapy } \\
\text { Electroconvulsive therapy } \\
\text { Social interventions } \\
\text { Leave } \\
\text { Transfer } \\
\text { Other specific assessments }\end{array}$ & $\begin{array}{l}2 \\
3 \\
1 \\
1 \\
1 \\
1 \\
3\end{array}$ & $\begin{array}{l}2.6 \\
3.9 \\
1.3 \\
1.3 \\
1.3 \\
1.3 \\
3.9\end{array}$ \\
\hline Discharge & 2 & 2.6 \\
\hline $\begin{array}{l}\text { Recommendation for } \\
\text { Mental Health Act assessment }\end{array}$ & 2 & 2.6 \\
\hline Physical investigations & 8 & 10.4 \\
\hline Physical monitoring or treatments & 8 & 10.4 \\
\hline Total physical health interventions & 11 & 14.3 \\
\hline Transfer to psychiatric intensive care unit & 3 & 3.9 \\
\hline Change in observations & 3 & 3.9 \\
\hline Urine drug screen & 3 & 3.9 \\
\hline Specific advice or information & 3 & 3.9 \\
\hline Obtained collateral information & 2 & 2.6 \\
\hline No action & 17 & 22.1 \\
\hline
\end{tabular}

admission reason and diagnosis. It is unclear why some higher trainees did not formulate diagnoses for the patients they reviewed, but there appears to be no significant differences between those diagnosed during the weekend or following later assessments.

Higher trainees performed or recommended a wide variety of interventions for patients, instituting some changes in $78.9 \%$ of cases. The most frequent action was to start some form of medication; this was done for $31.2 \%$ of patients. If increasing and stopping medication is also considered, then medication changes were performed in $47.8 \%$ of cases seen by the higher trainees. These were in addition to prescriptions made by admitting core trainees.
The next largest group of interventions were recommended physical investigations and interventions, again, which had not been instituted on admission. This occurred in $14.3 \%$ of patients reviewed. These varied from instituting monitoring of fluid and food intake to obtaining specific investigations, such as lithium levels.

A variety of other interventions were performed. It is reassuring that only 2 patients needed to have a recommendation for detention under the Mental Health Act completed. The others appear to be appropriately informally or already detained under the Mental Health Act. The limited number of discharges would be at least partially explained by this not being the proposed aim of the weekend reviews.

In $22.1 \%$ of patients seen over the weekends no action was taken by the higher trainee. This could be due to all reasonable interventions already having been performed by an experienced core trainee or patients requiring a period of observation before any definitive management plans are made.

Despite these interventions being initiated earlier than expected, there was no change in the average length of stay for patients who were eligible for new patient reviews. This could be explained by the interventions only being delivered 24-48 $\mathrm{h}$ earlier than they otherwise would have been. The reviews were also not intended to facilitate immediate discharge. A greater focus on expediting discharge over the weekend may have led to a reduced length of stay.

Although the overall number of serious untoward incidents was significantly higher in 2016 than 2015, there was no significant difference when they were restricted to those associated with acute out-of-hours services which would appear most clearly related to the introduction of weekend new patient reviews. The overall increase in incidents may be due to a continuing Trust drive to improve reporting with a view to improving services, rather than a true increase and so the figures are difficult to interpret accurately in this context.

This system did not require any changes in rota patterns for higher trainees. The system was such that the reviews were carried out during the scheduled 09:00 $\mathrm{h}$ to $21: 00 \mathrm{~h}$ shift, with reviews ceasing at 21:00 h so that patients could rest adequately without their evening or night being disrupted. On rare occasions when all the planned reviews could not be completed, they were postponed until the next day. Furthermore, as mentioned above, the focus of the reviews was not discharge; this prevented difficulties in coordinating with social care and other agencies during the weekend. The system used by the Trust enabled it to provide senior medical input 7 days a week in acute services without disrupting weekday working or leading to any of the other concerns raised by some authors. ${ }^{2}$

\section{Conclusions}

There has been increasing emphasis on providing more senior weekend medical input across all specialties. ${ }^{1}$ In psychiatry, the recommendations were mainly in terms of newly admitted patients.

Weekend reviews of newly admitted patients by higher trainees, with consultant support, is a feasible and appropriate method for providing senior input to these 
patients who could potentially remain on a ward for more than $48 \mathrm{~h}$ without being seen by any clinician more senior than a core trainee. This would not be considered appropriate in any other medical specialty. If we are to be committed to parity of esteem in healthcare, then it is reasonable for patients admitted to psychiatric wards to be reviewed by a senior clinician within $24 \mathrm{~h}$, as they would in any other hospital. ${ }^{3}$ This is particularly pertinent as the higher trainees provided some intervention in most patients, modifying medications in just under half of those admitted. It may be valuable to determine how this compares with patients reviewed during medical or surgical post-take rounds.

\section{About the authors}

Dr Michael Rutherford, Specialist Trainee 6, South West London and St George's Mental Health NHS Trust. Dr Mark Potter, Acting Medical Director and Consultant Psychiatrist, South West London and St George's Mental Health NHS Trust.

\section{References}

1 Academy of Medical Royal Colleges. Seven Day Consultant Present Care: Implementation Considerations. Academy of Medical Royal Colleges, 2013.

2 Keynejad R, Holt C, Rao R. 7 day services and psychiatry. Lancet Psychiatry 2016; 3: 197-9.

3 Bailey S, Thorpe L, Smith G. Whole-Person Care: From Rhetoric to Reality Achieving Parity between Mental and Physical Health (Occasional Paper OP88). Royal College of Psychiatrists, 2013.

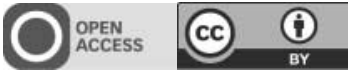

\title{
New models of care: a liaison psychiatry service for medically unexplained symptoms and frequent attenders in primary care
}

\author{
Janine Bestall, ${ }^{1}$ Najma Siddiqii, ${ }^{2,3}$ Suzanne Heywood-Everett, ${ }^{1,3}$ Charlotte Freeman, ${ }^{4}$ \\ Paul Carder, ${ }^{5,6}$ Mick James, ${ }^{5,6}$ Brendan Kennedy, $^{5,6}$ Angela Moulson, ${ }^{5,6}$ Allan House $^{1}$
}

BJPsych Bulletin (2017) 41, 340-344, doi: 10.1192/pb.bp.116.055731

\footnotetext{
'Leeds Institute of Health Sciences; ${ }^{2}$ University of York and Hull York Medical School; ${ }^{3}$ Bradford District Care NHS Foundation Trust; ${ }^{4}$ eMBED Health Consortium, Bradford; ${ }^{5} \mathrm{NHS}$ Airedale, Wharfedale and Craven Clinical Commissioning Group; ${ }^{6} \mathrm{NHS}$ Bradford Districts Clinical Commissioning Group

Correspondence to Janine Bestall (j.bestall@leeds.ac.uk)

First received 1 Dec 2016, final revision 3 Apr 2017, accepted 31 May 2017

(C) 2017 The Authors. This is an openaccess article published by the Royal College of Psychiatrists and distributed under the terms of the Creative Commons Attribution License (http:// creativecommons.org/licenses/by/ 4.0), which permits unrestricted use, distribution, and reproduction in any medium, provided the original work is properly cited.
}

Aims and method This paper describes the process of setting up and the early results from a new liaison psychiatry service in primary care for people identified as frequent general practice attenders with long-term conditions or medically unexplained symptoms. Using a rapid evidence synthesis, we identified existing service models, mechanisms to identify and refer patients, and outcomes for the service. Considering this evidence, with local contingencies we defined options and resources. We agreed a model to set up a service in three diverse general practices. An evaluation explored the feasibility of the service and of collecting data for clinical, service and economic outcomes.

Results High levels of patient and staff satisfaction, and reductions in the utilisation of primary and secondary healthcare, with associated cost savings are reported.

Clinical implications A multidisciplinary liaison psychiatry service integrated in primary care is feasible and may be evaluated using routinely collected data.

Declaration of interest J.B. was funded by NHS Airedale, Wharfdale and Craven Commissioning Group to write the report for this study. N.S. provided clinical expertise to the service described in this study.
Medically unexplained symptoms (MUS) and comorbid physical and mental health conditions place a significant burden on individuals and the economy. ${ }^{1,2}$ Annual costs of MUS have been estimated at $£ 3.1$ billion $^{3}$ and of comorbid conditions at $£ 18$ billion. ${ }^{4}$ Policy makers suggest innovative approaches be deployed to improve care for patients and make savings across the system. ${ }^{5}$
These patients frequently return to general practitioners (GPs) with unresolved and new complaints. Despite being referred to specialist services their problems remain, which is demoralising for all. Current primary care configurations do not adequately provide for this population. Standard secondary care mental health services rarely have staff with relevant expertise and are insufficiently close to primary 